\title{
EFFICACY OF DOUBLE DOSE VERSUS STANDARD DOSE ERGOCALCIF- EROL ON VITAMIN D STATUS AMONG PATIENTS WITH CHRONIC KID- NEY DISEASE
}

\author{
Siwimon Areepong, Ouppatham Supasyndh, Bancha Satirapoj*
}

Division of Nephrology, Department of Medicine, Phramongkutklao Hospital and Phramongkutklao College of Medicine, Bangkok, Thailand

\begin{abstract}
Background: Patients with chronic kidney disease (CKD) have an exceptionally high rate of 25-hydroxyvitamin D (25-OHD) deficiency. Modest supplementation with ergocalciferol to raise serum 25-OH-D levels might improve bone and mineral disorders in CKD. Limited evidence is available regarding dosage of ergocalciferol supplement in CKD populations.
\end{abstract}

Objectives: The study aimed to examine the effectiveness of double-dose ergocalciferol on serum 25-OHD, serum intact parathyroid hormone (PTH) levels and mineral and safety profiles compared with standard-dose ergocalciferol among CKD subjects.

Methods: The study employed a 12-week open labeled, randomized, controlled design among patients with CKD at stages III-IV and serum 25-OHD $<30 \mathrm{ng} / \mathrm{mL}$. Patients were randomized in 2 groups: standard dose treated with ergocalciferol as recommended by K/DOQI guidelines or double dose of ergocalciferol from recommendations. Serum testing including 25-OHD, intact PTH, phosphate and calcium was performed at baseline and week 12.

Results: Sixty-three patients were included [standard-dose group $(\mathrm{N}=30)$ and double-dose group $(\mathrm{N}=34)]$. At the end of the 12 weeks, $20(58.8 \%)$ patients in the double dose ergocalciferol group achieved sufficiency compared with $6(20 \%)$ patients in the standard dose ergocalciferol group $(p<0.05)$. A significant increase in serum 25-OHD levels $(13.6 \pm 9.9$ vs. $8.5 \pm 6.8 \mathrm{ng} / \mathrm{mL}, p=0.030)$ and decrease in serum PTH level group (-16.8 \pm 26.4 vs. $-0.3 \pm 26.8 \mathrm{pg} / \mathrm{mL}, p=0.030)$ was found in the double-dose group compared with the standard-dose group. No adverse effect was associated with the treatment.

Conclusion: The study demonstrated that high dose oral ergocalciferol had higher efficacy to increase serum 25-OHD and decrease serum PTH levels among patients with CKD than standard-dose ergocalciferol after 12 weeks of treatment.

Keywords: Hyperparathyroidism, Chronic kidney disease, 25-hydroxyvitamin D deficiency, Ergocalciferol

J Southeast Asian Med Res 2020; 4(2): 59-66

http://www.jseamed.org

*Correspondence to:

Satirapoj B, Division of Nephrology, Department of Medicine, Phramongkutklao Hospital and Phramongkutklao College of Medicine, Bangkok, Thailand

E-mail: satirapoj@yahoo.com

Received: 24 June 2020

Revised: 15 November 2020

Accepted: 01 December 2020 


\section{Introduction}

Vitamin D deficiency has a significantly higher prevalence in chronic kidney disease $(\mathrm{CKD})^{(1)}$ and is associated with increased mortality in CKD populations. ${ }^{(1-3)}$ Current evidence has indicated that low serum 25-hydroxyvitamin D (25-OHD) concentrations are related to higher albuminuria, a rapid decline in renal function and progression to dialysis among predialysis patients with CKD. ${ }^{(4-6)}$ Replete 25-OHD concentrations using vitamin D supplementation on clinical outcomes needs to be evaluated in this population.

Secondary hyperparathyroidism, attributed to vitamin D deficiency, has developed among patients with CKD progression. ${ }^{(7)}$ Several studies have indicated that vitamin D supplementation to optimal vitamin D status provided parathyroid hormone $(\mathrm{PTH})$ suppression in early stage $\mathrm{CKD}^{(8,9)}$, but the results were discordant concerning beneficial effects of vitamin D supplementation. ${ }^{(10)}$ Current guidelines support native vitamin D supplementation in CKD based on extrapolation from cohorts conducted in the general population. An initial study demonstrated that high dose ergocalciferol supplement for eight weeks produced benefits on serum 25-OHD and PTH level among subjects with CKD. ${ }^{(11)}$ More clinical studies need to test the optimal target of serum 25-OHD concentrations after vitamin D therapy in CKD populations. ${ }^{(12)}$ The primary aim of the study was to determine whether double-dose ergocalciferol supplementation for 12 weeks was sufficient to maintain optimal vitamin D status and reduce serum PTH levels among patients with CKD compared with standard dose ergocalciferol supplementation.

\section{Methods}

This open labeled, randomized controlled trial compared two dosing regimens of ergocalciferol among patients with CKD stages III to V at Phramongkutklao Hospital and College of Medicine from October 2013 to September 2014. Patients were included in the study if they were aged $\geq 18$ years, had estimated GFR $<60 \mathrm{ml} / \mathrm{min} / 1.73 \mathrm{~mm}^{2}$ by CKD-EPI creatinine base formula and serum $25-\mathrm{OH}-\mathrm{D}<30 \mathrm{ng} / \mathrm{dL}$. Patients were excluded if they had vitamin D analog supplement within 12 weeks, serum hypercalcemia, hyperphosphatemia, malabsorption syndrome, active malignancy or chronic illness with life expectancy $<6$ months. The study was approved by the Institutional Review Board of the Royal Thai Army Medical Department. Written informed consent was obtained from all subjects.

Study patients were randomized by a block of four randomizations assigned to two groups. The sample size calculated from the previous study was used to determine the mean difference of intact-PTH between standard dose ergocalciferol and double dose ergocalciferol. ${ }^{(11)}$ To test the hypothesis, approximately 28 individuals per group plus dropout rate $20 \%$ were selected. Finally, 64 patients were included in this study. The standard dose ergocalciferol was prepared according to regimen based on KDOQI recommendations: (50,000 IU of ergocalciferol once weekly for 8 weeks for serum 25-OHD $<5 \mathrm{ng} / \mathrm{mL}, 50,000 \mathrm{IU}$ of ergocalciferol once weekly for 4 weeks for serum 25-OHD $5-15 \mathrm{ng} / \mathrm{mL}$ and 50,000 IU of ergocalciferol once monthly for 8 weeks for serum 25-OHD 16-30 ng/mL and then 50,000 IU of ergocalciferol once monthly). The double dose ergocalciferol was prepared from the KDOQI recommended dose. Follow-up visits were performed at 4,8 , and 12 weeks and at start and end of treatment with serum calcium, phosphorus, intact PTH and 25-OHD levels were measured. A 12-week follow-up visit was included to assess response durability. Serum total 25-OHD and intact-PTH levels were measured using electrochemiluminescence binding assay (Elecsys and Cobas e 601 immunoassay analyzers, Roche Diagnostics).

The primary endpoint was achieving vitamin D sufficiency $(25-\mathrm{OHD}>30 \mathrm{ng} / \mathrm{mL})$ at the end of the 12-week treatment period. Secondary endpoints included measures of mineral metabolism (calcium, phosphate and parathyroid hormone [PTH] levels). Mild, moderate and severe vitamin $\mathrm{D}$ deficiency were defined as serum 25 OH-D 16-30, 5-15 and $<5 \mathrm{ng} / \mathrm{mL}$, respectively. Adverse events that were or were not considered to be related to treatment were monitored during the study. 


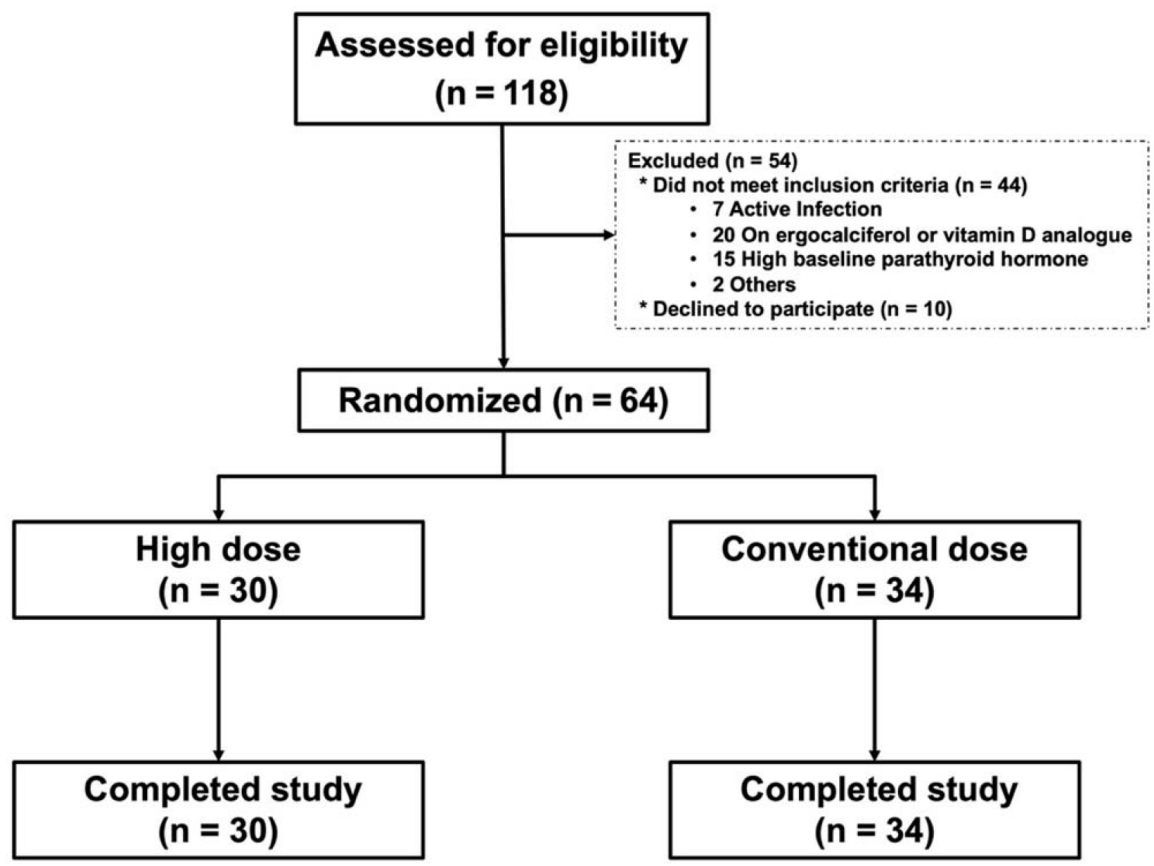

Figure 1. Flow chart study

Table 1. Baseline characteristics of enrolled participants

\begin{tabular}{lccc}
\hline & $\begin{array}{c}\text { Standard Dose } \\
\text { Ergocalciferol } \\
(\mathrm{N}=30)\end{array}$ & $\begin{array}{c}\text { Double Dose Ergo- } \\
\text { calciferol (N=34) }\end{array}$ & $p$-value \\
& $15(50)$ & & \\
\hline Male (\%) & $69.2 \pm 11.6$ & $66.9 \pm 13.6$ & 0.547 \\
Age (years) & $66.6 \pm 15.0$ & $63.6 \pm 13.1$ & 0.479 \\
Body weight $(\mathrm{kg})$ & $25.0 \pm 5.9$ & $23.7 \pm 4.1$ & 0.404 \\
Body mass index (kg/m²) & $136.2 \pm 13.9$ & $139.5 \pm 18.3$ & 0.297 \\
Systolic blood pressure (mmHg) & $74.9 \pm 9.0$ & $76.8 \pm 13.2$ & 0.435 \\
Diastolic blood pressure (mmHg) & & & \\
Comorbid diseases (N, \%) & $27(90)$ & $30(90.91)$ & 1.000 \\
- Hypertension & $14(46.7)$ & $15(45.5)$ & 0.923 \\
- Type 2 diabetes & $18(60)$ & $22(66.7)$ & 0.583 \\
- Dyslipidemia & $3(10)$ & $3(9.1)$ & 1.000 \\
- Cardiovascular disease & $5(16.7)$ & $3(9.1)$ & 0.462 \\
- Gout & & & \\
Chronic kidney disease staging (N, \%) & $21(70)$ & $20(60.61)$ & \\
- Stage III & $8(26.7)$ & $10(30.3)$ & 0.575 \\
- Stage IV & $1(3.3)$ & $3(9.09)$ & 0.516 \\
- Stage V & & & \\
Vitamin D status (N, \%) & $17(56.7)$ & $16(48.48)$ & $16(48.48)$ \\
- Mild vitamin D deficiency & $11(36.7)$ & $1(3.03)$ & \\
- Moderate vitamin D deficiency & $2(6.7)$ & & \\
- Severe vitamin D deficiency & & & \\
\hline
\end{tabular}

Data are mean $\pm S D$ and percentage. Mild, moderate and severe vitamin D deficiency are defined as serum $25 \mathrm{OH}-\mathrm{D}$ 16-30, 5-15 and $<5 \mathrm{ng} / \mathrm{mL}$, respectively. The standard dose ergocalciferol was prepared according to regimen based on KDOQI recommendations and the double dose ergocalciferol was prepared from KDOQI recommended dose 
Study patients were followed for toxicity and compliance every four weeks during treatment. Any patients with serum calcium $>10.5 \mathrm{mg} / \mathrm{dL}$, serum phosphate $>5.5 \mathrm{mg} / \mathrm{dL}$ and serum 25 $\mathrm{OH}-\mathrm{D}>80 \mathrm{ng} / \mathrm{mL}$ were immediately withdrawn from the study and the primary care physician was notified. Pill counts were used to track compliance.

\section{Statistical Analysis}

Clinical, and laboratory data were collected and entered in an electronic database. Categorical data were compared using the Chi-square test and Fisher's exact test. Comparison of continuous variables between two groups was tested using the Student t-test and Mann-Whitney $\mathrm{U}$ test. Paired t-tests and Wilcoxon signed ranks sum test were used to analyze the differences between various parameters at baseline and after treatment. All statistical analyses were performed using SSPS Software Program, Version 16.1 and $p<0.05$ was considered significant. Values were expressed as mean $\pm \mathrm{SD}$ and percentage.

\section{Results}

A total of 118 patients in the outpatient department were screened for possible study enrollment (Figure 1). Sixty-three patients were eligible according to the entry criteria. Thirty patients were assigned to the standard dose ergocalciferol group and 34 patients were assigned to the double dose ergocalciferol group. Two groups were similar with respect to age, sex, clinical characteristics and baseline laboratory profiles including serum $25(\mathrm{OH}) \mathrm{D}$, calcium, phosphate and PTH levels (Tables 1 and 2). Mean serum 25-OHD level was $18.7 \pm 7.2 \mathrm{ng} / \mathrm{mL}$ and mean plasma intact PTH level was $94.7 \pm 68.5 \mathrm{pg} / \mathrm{mL}$. Thirty-three patients $(51.5 \%)$ had mild vitamin D deficiency (25-OHD level, 16 to $30 \mathrm{ng} / \mathrm{mL}), 27$ patients $(42.8 \%)$ had moderate vitamin D deficiency (25-OHD level, 5 to $15 \mathrm{ng} / \mathrm{mL}$ ) and 3 patients (4.7\%) had severe vitamin D deficiency (25-OHD level, $<5 \mathrm{ng} / \mathrm{mL})$. In total, 41 patients $(66.6 \%)$ had CKD stage III, 18 patients $(28.5 \%)$ had CKD stage IV and 3 patients $(4.7 \%)$ had CKD stage V.

Table 2. Baseline biochemical data of enrolled participants

\begin{tabular}{lccc}
\hline & $\begin{array}{c}\text { Standard Dose } \\
\text { Ergocalciferol }\end{array}$ & $\begin{array}{c}\text { Double Dose } \\
\text { Ergocalciferol } \\
(\mathrm{N}=34)\end{array}$ & $p$-value \\
& $(\mathrm{N}=30)$ & & \\
\hline Serum 25-OHD (ng/mL) & $18.9 \pm 7.3$ & $18.2 \pm 7.4$ & 0.660 \\
Intact PTH (pg/mL) & $94.8 \pm 70.7$ & $94.6 \pm 65.4$ & 0.990 \\
BUN (mg/dL) & $28.8 \pm 16.4$ & $29.9 \pm 19.1$ & 0.815 \\
Cr (mg/dL) & $4.2 \pm 12.1$ & $2.1 \pm 0.9$ & 0.321 \\
Serum calcium (mg/dL) & $9.1 \pm 0.4$ & $9.3 \pm 0.4$ & 0.097 \\
Serum phosphate (mg/dL) & $3.6 \pm 1.3$ & $3.5 \pm 0.4$ & 0.719 \\
Hb $(\mathrm{g} / \mathrm{dL})$ & $11.42 \pm 1.55$ & $11.84 \pm 1.93$ & 0.357 \\
Plasma sodium (mmol/L) & $138.79 \pm 3.19$ & $139.86 \pm 2.45$ & 0.138 \\
Plasma potassium (mmol/L) & $4.21 \pm 0.47$ & $4.34 \pm 0.54$ & 0.137 \\
Plasma chloride (mmol/L) & $103.42 \pm 3.82$ & $104.46 \pm 3.24$ & 0.247 \\
Plasma bicarbonate $(\mathrm{mmol} / \mathrm{L})$ & $23.92 \pm 3.22$ & $23.6 \pm 3.3$ & 0.699 \\
\hline
\end{tabular}

Data are mean $\pm S D$. No significant difference was detected in both groups. Standard dose ergocalciferol was prepared according to regimen based on KDOQI recommendations and the double dose ergocalciferol was prepared from the KDOQI recommended dose. 
Table 3. Change of serum 25-OHD, parathyroid hormone, calcium, and phosphate levels after ergocalciferol treatment

\begin{tabular}{|c|c|c|c|}
\hline & $\begin{array}{l}\text { Standard Dose Ergo- } \\
\text { calciferol } \\
(\mathrm{N}=30)\end{array}$ & $\begin{array}{l}\text { Double Dose Ergo- } \\
\text { calciferol } \\
(\mathrm{N}=34)\end{array}$ & $p$-value \\
\hline \multicolumn{4}{|c|}{ Serum 25-OHD (ng/mL) } \\
\hline - Baseline & $18.9 \pm 7.3$ & $18.2 \pm 7.4$ & 0.660 \\
\hline - At 12 weeks & $27.9 \pm 10.1$ & $32.1 \pm 9.0$ & 0.111 \\
\hline - $\quad p$-value & $<0.001$ & $<0.001$ & \\
\hline - Mean change & $8.5 \pm 6.8$ & $13.6 \pm 9.9$ & 0.030 \\
\hline \multicolumn{4}{|l|}{ Intact PTH (pg/mL) } \\
\hline - Baseline & $94.8 \pm 70.7$ & $94.6 \pm 65.4$ & 0.990 \\
\hline - At 12 weeks & $96.6 \pm 82.9$ & $77.4 \pm 52.4$ & 0.326 \\
\hline - $\quad p$-value & 0.961 & 0.004 & \\
\hline - Mean change & $-0.3 \pm 26.8$ & $-16.8 \pm 26.4$ & 0.030 \\
\hline \multicolumn{4}{|l|}{ Serum calcium $(\mathrm{mg} / \mathrm{dL})$} \\
\hline - Baseline & $9.1 \pm 0.4$ & $9.3 \pm 0.4$ & 0.097 \\
\hline - $\quad$ At 12 weeks & $9.3 \pm 0.4$ & $9.0 \pm 1.2$ & 0.833 \\
\hline - $\quad p$-value & 0.791 & 0.562 & \\
\hline - Mean change & $-0.2 \pm 1.2$ & $-0.3 \pm 1.1$ & 0.743 \\
\hline \multicolumn{4}{|c|}{ Serum phosphate (mg/dL) } \\
\hline - $\quad$ Baseline & $3.6 \pm 1.3$ & $3.5 \pm 0.4$ & 0.719 \\
\hline - At 12 weeks & $3.6 \pm 0.8$ & $3.5 \pm 0.5$ & 0.561 \\
\hline - $\quad p$-value & 0.338 & 0.584 & \\
\hline - Mean change & $0.0 \pm 1.4$ & $0.1 \pm 0.5$ & 0.899 \\
\hline
\end{tabular}

Data are mean $\pm S D$. The standard dose ergocalciferol was prepared according to regimen based on KDOQI recommendations and the double dose ergocalciferol was prepared from KDOQI recommended dose.

After 12 weeks of supplement with ergocalciferol, $20(58.8 \%)$ patients in the double dose ergocalciferol group achieved sufficiency compared with $6(20 \%)$ patients in the standard dose ergocalciferol group $(p<0.05)$ (Figure 2). A significant increase was observed in serum 25 -OHD levels from $18.9 \pm 7.3$ to $27.9 \pm 10.1 \mathrm{ng} /$ $\mathrm{mL}$ in the standard dose ergocalciferol group $(p<0.001)$ and $18.2 \pm 7.4$ to $32.1 \pm 9.0 \mathrm{ng} / \mathrm{mL}$ in the double dose ergocalciferol group $(p<0.001)$. Also, a significantly greater increase of serum 25-OHD levels was found in the double dose ergocalciferol group compared with the standard dose ergocalciferol group (mean change $13.6 \pm 9.9$ vs. $8.5 \pm 6.8, p=0.030$, respectively)
Regarding secondary outcomes, serum PTH levels significantly decreased from $94.6 \pm 65.4$ to $77.4 \pm 52.4$ at 12 -weeks $(p=0.004)$ in the double dose ergocalciferol group, while no change was found in the standard dose ergocalciferol group. A significantly greater decrease in serum intact PTH was observed in the double dose ergocalciferol group as compared with the standard dose ergocalciferol group (mean change $-16.8 \pm 26.4$ vs. $-0.3 \pm 26.8, p=0.030$, respectively) (Table 3). No differences in serum $\mathrm{Ca}$ and phosphate were detected between groups at any of the study visits, and no patients exhibited any serious adverse events during the study.

(Table 3). 


\section{Vitamin D sufficiency after 12 weeks of ergocalciferol supplement}

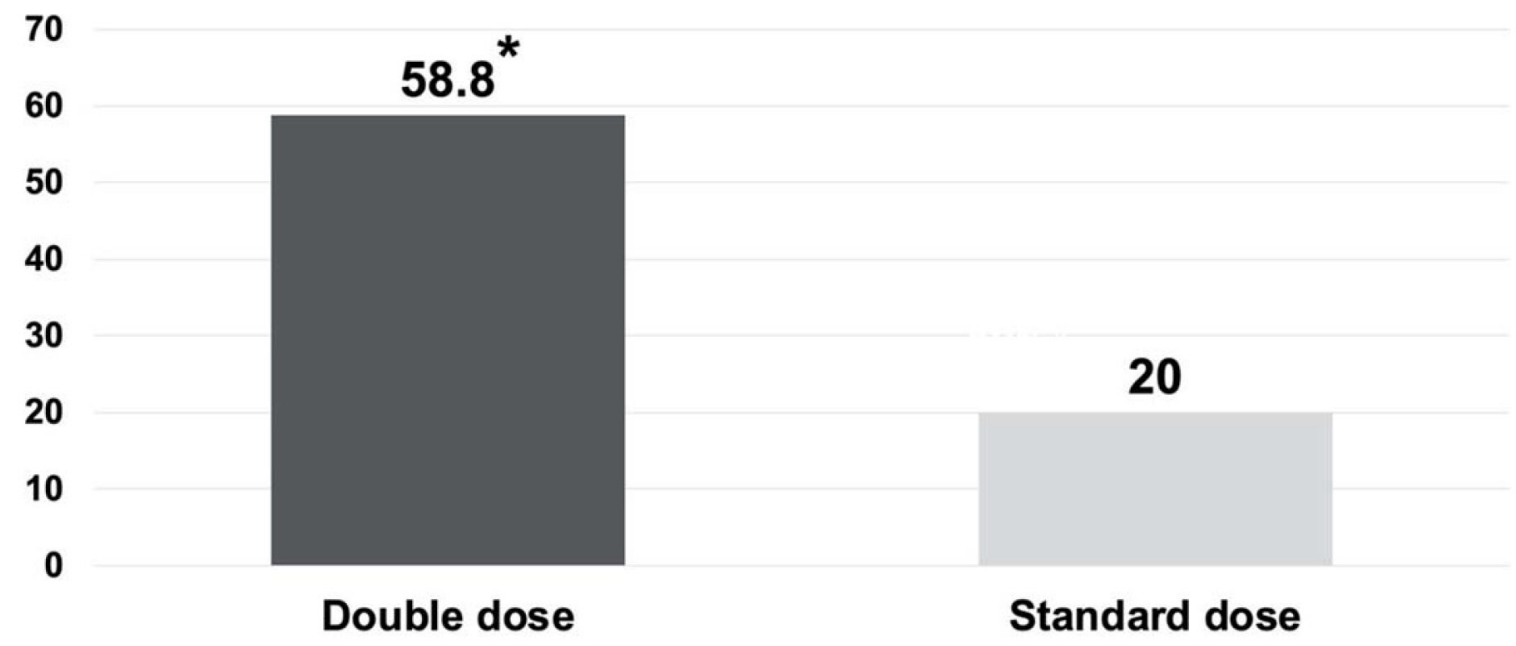

Percentage of patients with vitamin sufficiency (serum $25-\mathrm{OH}-\mathrm{D} \geq 30 \mathrm{ng} / \mathrm{mL}$ ) was difference in the both treatments with ${ }^{*} \mathrm{p}$ value $<0.05$.

Figure 2. Vitamin D status after treatment with double dose ergocalciferol compared with standard dose ergocalciferol

\section{Discussion}

Progressive vitamin D deficiency worsens from CKD stages III-IV. Extrarenal conversion of $25(\mathrm{OH}) \mathrm{D}$ to $1,25(\mathrm{OH}) 2 \mathrm{D}$ by macrophages leads to autocrine and paracrine effects on immune function and inflammatory responses. ${ }^{(13)}$ Thus, replacing 25-OHD by native vitamin D supplementation regimens would be beneficial even among patients with CKD while supplementation regimens remain debatable among patients with CKD. Many regimens using either ergocalciferol or cholecalciferol have been reported and data are limited regarding appropriate dosing, safety and efficacy. Our study indicated that double dose ergocalciferol was more efficient to increase serum vitamin $D$ levels and decrease serum PTH levels. No notable persistent changes were observed regarding serum calcium and phosphate levels.

Vitamin D deficiency has been suggested to constitute a risk factor for hyperparathyroidism and low serum $25(\mathrm{OH}) \mathrm{D}$ levels cause a negative calcium balance, high bone turnover, secondary hyperparathyroidism and decreased bone mineraldensity among patients with CKD. ${ }^{(14,15)}$ Conventional dose vitamin D supplement including

ergocalciferol supplement showed benefit concerning level of PTH in only early CKD stage III $^{(16)}$, but other studies failed to show benefit to control of PTH among patients with CKD stages 3 to $4 .^{(17,18)}$ Inadequate and short duration of vitamin $\mathrm{D}$ supplement might not be sufficient to correct abnormal bone metabolism. Serum 25OH-D level correlated positively with serum calcitriol level and negatively with serum PTH level among advanced patients with CKD. ${ }^{(2)}$ Later studies have found that high dose ergocalciferol or cholecalciferol supplement produced positive effects in suppressing PTH level among subjects with CKD. ${ }^{(11,19,20)}$ One meta-analysis and systematic review suggested that native vitamin D supplement improved serum 25-OHD and was associated with declined PTH levels with low incidence of hypercalcemia and hyperphosphatemia among nondialysis patients with CKD. ${ }^{(21)}$ This was consistent with our finding that oral high dose ergocalciferol for 12 weeks had a beneficial effect in decreasing serum PTH and achieving vitamin D sufficiency among patients with CKD. Possibly patients with advanced CKD stages may require a higher 
dose of native vitamin $\mathrm{D}$ supplement to increase biologically active vitamin D production, reversing resistance to paricalcitol induction and suppressing parathyroid gland enlargement. ${ }^{(22)}$ The discrepancies of native vitamin dosage in the general population and among patients with CKD might be related to differences in gastrointestinal absorption, liver metabolism and vitamin D receptor genetic polymorphisms. ${ }^{(24)}$ We assessed any potential adverse effects of short term vitamin $\mathrm{D}$ treatment. We found no differences in adverse events between groups, including hypercalcemia, hyperphosphatemia, hospitalizations and cardiovascular events. The finding is consistent with previous data of patients with CKD. ${ }^{(22)}$ One limitation was single center studies may limit generalizability to other populations. Our study was also limited by a short follow-up of 12 weeks without apparent treatment-related benefits on cardiovascular events and renal outcomes among patients with CKD. Further study is needed to confirm these outcomes.

In conclusion, replacing double dose ergocalciferol over 12 weeks resulted in increased vitamin D sufficiency status and decreased PTH levels among patients with CKD stages 3 to 5 without any hypercalcemia or hyperphosphatemia compared with standard dose ergocalciferol.

\section{Acknowledgments}

The authors wish to thank the staff of the Division of Nephrology and Biomedical Clinical Research Center, Phramongkutklao Hospital for their assistance with the study. The study was sponsored by a grant from the Department of Medicine, Phramongkutklao Hospital and Phramongkutklao College of Medicine.

\section{Potential conflicts of interest}

The authors declare they have no potential conflicts of interest.

\section{References}

1. Yadav AK, Kumar V, Kumar V, Banerjee D, Gupta KL, Jha V. The Effect of Vitamin D Supplementation on Bone Metabolic Markers in Chronic Kidney Disease. J Bone Miner Res 2018; 33: 404-9.
2. Gonzalez EA, Sachdeva A, Oliver DA, Martin KJ. Vitamin D insufficiency and deficiency in chronic kidney disease. A single center observational study. Am J Nephrol 2004; 24: 503-10.

3. Jayedi A, Soltani S, Shab-Bidar S. Vitamin D status and all-cause mortality in patients with chronic kidney disease: A systematic review and dose-response meta-analysis. J Clin Endocrinol Metab 2017; 102: 2136-45.

4. Xie S, Huang L, Cao W, et al. Association between serum 25-hydroxyvitamin $\mathrm{D}$ and diabetic kidney disease in Chinese patients with type 2 diabetes. PLoS One 2019; 14: e0214728.

5. Pilz S, Iodice S, Zittermann A, Grant WB, Gandini S. Vitamin D status and mortality risk in CKD: a meta-analysis of prospective studies. Am J Kidney Dis 2011; 58: 374-82.

6. Ravani P, Malberti F, Tripepi G, et al. Vitamin D levels and patient outcome in chronic kidney disease. Kidney Int 2009; 75: 88-95.

7. Levin A, Bakris GL, Molitch M, et al. Prevalence of abnormal serum vitamin D, $\mathrm{PTH}$, calcium, and phosphorus in patients with chronic kidney disease: results of the study to evaluate early kidney disease. Kidney Int 2007; 71: 31-8.

8. Alvarez JA, Law J, Coakley KE, et al. Highdose cholecalciferol reduces parathyroid hormone in patients with early chronic kidney disease: a pilot, randomized, doubleblind, placebo-controlled trial. Am J Clin Nutr 2012; 96: 672-9.

9. Dogan E, Erkoc R, Sayarlioglu H, Soyoral Y, Dulger H. Effect of depot oral cholecalciferol treatment on secondary hyperparathyroidism in stage 3 and stage 4 chronic kidney diseases patients. Ren Fail 2008;30:407-10.

10. Alvarez J, Wasse H, Tangpricha V. Vitamin D supplementation in pre-dialysis chronic kidney disease: A systematic review. Dermatoendocrinol 2012; 4: 118-27.

11. Thimachai P, Supasyndh O, Chaiprasert A, Satirapoj B. Efficacy of High vs. Conventional Ergocalciferol Dose for Increasing 25Hydroxyvitamin D and Suppressing 
Parathyroid Hormone Levels in Stage III-IV CKD with Vitamin D Deficiency/Insufficiency: A Randomized Controlled Trial. J Med Assoc Thai 2015; 98: 643-8.

12. Alfieri C, Ruzhytska O, Vettoretti S, Caldiroli L, Cozzolino M, Messa P. Native Hypovitaminosis D in CKD Patients: From Experimental Evidence to Clinical Practice. Nutrients 2019; 11: 1918.

13. Hewison M. Vitamin D and immune function: autocrine, paracrine or endocrine? Scand J Clin Lab Invest Suppl 2012; 243: 92-102.

14. Goldsmith DJ. Pro: Should we correct vitamin D deficiency/insufficiency in chronic kidney disease patients with inactive forms of vitamin D or just treat them with active vitamin D forms? Nephrol Dial Transplant 2016; 31: 698-705.

15. Lee YH, Kim JE, Roh YH, et al. The combination of vitamin $\mathrm{D}$ deficiency and mild to moderate chronic kidney disease is associated with low bone mineral density and deteriorated femoral microarchitecture: results from the KNHANES 2008-2011. J Clin Endocrinol Metab 2014; 99: 3879-88.

16. Zisman AL, Hristova M, Ho LT, Sprague SM. Impact of ergocalciferol treatment of vitamin D deficiency on serum parathyroid hormone concentrations in chronic kidney disease. Am J Nephrol 2007; 27: 36-43.

17. Bhan I, Dobens D, Tamez H, et al. Nutritional vitamin D supplementation in dialysis: a randomized trial. Clin J Am Soc Nephrol 2015; 10: 611-9.

18. Kovesdy CP, Lu JL, Malakauskas SM, Andress DL, Kalantar-Zadeh K, Ahmadzadeh S. Paricalcitol versus ergocalciferol for secondary hyperparathyroidism in CKD stages 3 and 4: a randomized controlled trial. Am J Kidney Dis 2012; 59: 58-66.

19. Al-Aly Z, Qazi RA, Gonzalez EA, Zeringue A, Martin KJ. Changes in serum 25-hydroxyvitamin D and plasma intact PTH levels following treatment with ergocalciferol in patients with CKD. Am J Kidney Dis 2007; $50: 59-68$.

20. Oksa A, Spustova V, Krivosikova Z, et al. Effects of long-term cholecalciferol supplementation on mineral metabolism and calciotropic hormones in chronic kidney disease. Kidney Blood Press Res 2008; 31: 322-9.

21. Kandula P, Dobre M, Schold JD, Schreiber MJ, Jr., Mehrotra R, Navaneethan SD. Vitamin D supplementation in chronic kidney disease: a systematic review and meta-analysis of observational studies and randomized controlled trials. Clin J Am Soc Nephrol 2011; 6: 50-62.

22. Arcidiacono MV, Yang J, Fernandez E, Dusso A. The induction of C/EBPbeta contributes to vitamin D inhibition of ADAM17 expression and parathyroid hyperplasia in kidney disease. Nephrol Dial Transplant 2015; 30: 423-33.

23. Satirapoj B, Limwannata P, Chaiprasert A, Supasyndh O, Choovichian P. Vitamin D insufficiency and deficiency with stages of chronic kidney disease in an Asian population. BMC Nephrol 2013; 14: 206.

24. Levin GP, Robinson-Cohen C, de Boer IH, et al. Genetic variants and associations of 25-hydroxyvitamin D concentrations with major clinical outcomes. JAMA 2012; 308: 1898-905. 